\title{
Mandibular Canal Location and Cortical Bone Thickness in Males and Females of Different Age Groups: A Cone-beam Computed Tomography Study
}

\author{
Sherif Shafik El-Bahnasy ${ }^{1 *(\mathbb{D})}$, Magdy Youakim², ${ }^{2,3}$, Mohamed Shamel $^{1}$ (D), Hisham El Sheikh ${ }^{1}$ (D) \\ ${ }^{1}$ Department of Oral Radiology, Faculty of Dentistry, The British University in Egypt, Cairo, Egypt; ${ }^{2}$ Department of Anatomy, \\ Faculty of Medicine, Cairo University, Giza, Egypt; ${ }^{3}$ Department of Anatomy, Faculty of Dentistry, The British University in \\ Egypt, Cairo, Egypt
}

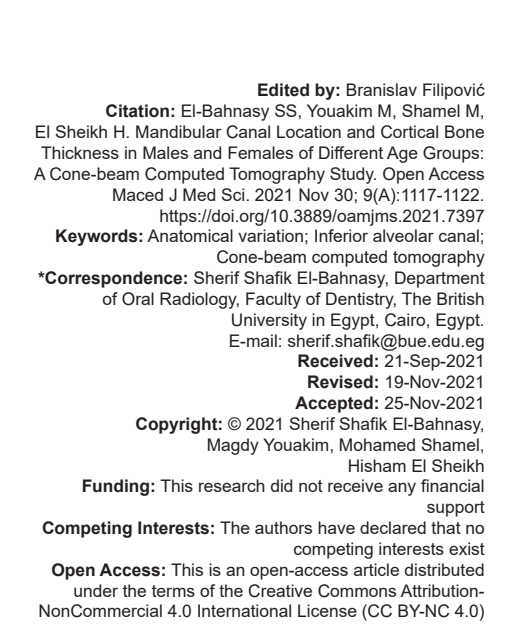

\begin{abstract}
AIM: The purpose of the study was to measure and compare the prevalence of mandibular canal (MC) location variations in regard to mandibular first molars in both genders at different age groups.

METHODS: A retrospective study was performed on 80 cone-beam computed tomography scans. Distance between $\mathrm{MC}$ and apical apices of first molars, buccal and lingual cortical plates was measured in both sides.

RESULTS: 80 scans with 160 sides were analyzed. Distances was measured bilaterally for all scans with mean $(5.22$ $\pm 0.77)$ in men versus $(4.1 \pm 0.7)$ in women at group age $31-40$ apical to apices of first molars. The mean was (3.77 $\pm 0.62)$ in men versus $(2.81 \pm 0.47)$ in women at same age group at buccal side, lingually the mean was $(4.02 \pm 0.67)$ in men versus $(3.67 \pm 0.26)$ in women in the same age group.

CONCLUSION: Our study showed that there were decrease in measurements in older age group in both genders and in female groups more than male groups but with no statistical significant difference.
\end{abstract}

\section{Introduction}

The mandibular canal $(\mathrm{MC})$ is the main neurovascular canal in the mandible it begins at the mandibular foramen present in the medial side of the ramus of the mandibular. It runs downward and forward in the ramus, and then runs horizontally forward in the body, till the mental foramen, which is situated mesial, distal, or between apices of the roots of premolars. Commonly, the MC crosses from the lingual to the buccal side of the mandible lying nearly midway between the buccal and lingual cortical plates of bone at the first molar. It is placed under the alveoli of the teeth and connects with them by small openings [1], [2], [3].

MC transmits inferior alveolar neurovascular bundle, which includes: The inferior alveolar nerve (IAN) and inferior alveolar vessels (IAV). The IAN is the largest branch of trigeminal nerve posterior division. It enters the mandible through mandibular foramen. It ends by dividing into mental nerve which exits through the mental foramen, to supply the skin of lower lip and chin and the incisive nerve which pass through the mandibular incisive canal to supplies canine and incisor teeth. The IAN lies below the IAV, and the artery is usually located lingual to the vein [4], [5].

IAN is exposed to iatrogenic injuries during numerous dental procedures including surgical procedures such as fixation of mandibular fracture, impacted third molar tooth extraction, and placement of dental implant, as well as non-surgical procedures as root canal treatment. Injury of the IAN results in numbness, neuropathic pain or anesthesia of the lower lip and chin. These complications may be caused either by direct injury to the IAN or by indirect injury due to compression caused hematoma of the inferior alveolar artery [6].

Dentists should be aware of the position of MC before attempting dental implant or any invasive dental procedures in the lower jaw to avoid potential injury of IAN [7], [8].

From the above, it is clear that determination of cortical bone thickness, apical available bone, location of inferior alveolar canal (IAC) at the implant site, is a 
critical issue influencing the success of dental implant procedure, since the primary stability of the implant is a key point in a successful dental implant, and also avoiding the iatrogenic IAC trauma during dental implant procedure [9], [10], [11].

\section{Aim}

Several papers tried to determine the site of the MC, most of them lack correlation to age and to sex, making results not useful, as these data vary greatly according to age and sex. In this study, we use dental cone-beam computed tomography (CBCT) to determine the distance between the roots apices of the mandibular molars and the $\mathrm{MC}$ and to measure the cortical bone thickness in different age groups of both sexes, helping dentists to be familiar with these values, to determine the optimal implant length, to ensure successful implant surgery and reducing complications of iatrogenic injuries of IAN.

\section{Subjects and Methods}

CBCT scans of 80 patients with mean age 40.5 in Dental Hospital of The British University in Egypt referred for several clinical reasons were collected retrospectively from the dental hospital database. These scans were analyzed to measure three parameters DA, DB, and DL (Figure 1a and b).

Subjects were sub grouped according to age and sex.

\footnotetext{
- Group 1 (20 patients): Ten males and ten females, between 21 and 30 years.

- Group 2 (20 patients): Ten males and ten females, between 31 and 40 years.

- Group 3 (20 patients): Ten males and ten females, between 41 and 50 years.

- Group 4 (20 patients): Ten males and ten females, between 51 and 60 years.
}

In this study, three parameters were measured in millimeter.

1. DA: The mean distance between the root apices of the mandibular molars and the MC

2. DB: The distance from the MC to the buccal cortical plate of the mandible

3. DL: The distance from the $M C$ to the lingual cortical plate of the mandible.

CBCT examination was performed using CBCT machine (Scanora 3DX) (Soredex, Tuusula, Finland, high-resolution program, voxel size $0.2 \mathrm{~mm}$ ), this machine with CMOS flat panel detector and isotropic voxel size of $133 \mu \mathrm{m}$ using field of view $(8 \times 10 \mathrm{~cm})$ and high definition mode with exposure parameters of; $90 \mathrm{Kvp}, 10 \mathrm{~m} . \mathrm{A}$, exposure time $10 \mathrm{~s}$, effective exposure time $6 \mathrm{~s}$, and $0.5 \mathrm{~mm}$ Focal spot. All images were visualized with the Ondemand 3DTM software (Version 1.0.10.6388, CyberMed Inc, Seoul, Korea) by two trained and calibrated oral and maxillofacial radiologist observers. Eventual disagreements were discussed and consensus was reached. After curve adjustment in each project, the distance from apices of mesial and distal root to the IAC was measured in the cross-section reconstruction view and the mean distance for every patient was calculated for each side. The distance from IAC and the buccal, lingual cortical plate of bone was measured in the crosssectional reconstruction view.

The exclusion criteria for this study were as follows: The presence of a lesion at the region of interest; history of orthodontic treatment; endodontic treatment, long-term edentulism; alveolar bone resorption or bone loss; and evidence of abnormal anatomy.

\section{Statistical analysis}

The data are expressed as mean \pm standard deviation (SD). The results were analyzed through one-way analysis of variance to compare between groups, followed by Bonferroni's test post hoc analysis. Unpaired t-test was used to compare between the male and female groups of same age. All tests and figures
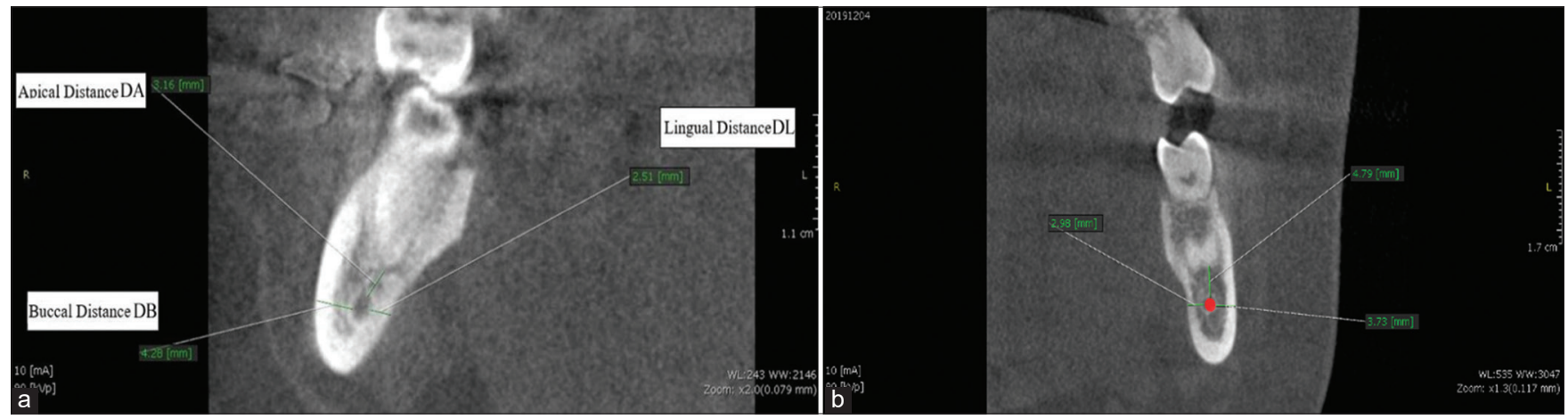

Figure 1: $(a$ and b) Cone-beam computed tomography cross-section of a mandibular molar root. DA (distance from root apex to the mandibular canal), $D B$ (distance from mandibular canal to the outer boundary of the buccal cortical plate), $D L$ (distance from mandibular canal to the outer boundary of the lingual cortical plate) 
were done by GraphPad Prism version 7.00 (GraphPad Software, San Diego, CA). $p<0.05$ was statistically significant.

\section{Results}

A total of 80 patients, 40 males and 40 females, were included in this study. Male and female patients were further subdivided into four groups according to their age: Group 1 patients between 21 and 30 years, Group 2 patients between 31 and 40 years, Group 3 patients between 41 and 50 years, and Group 4 patients between 51 and 60 years.

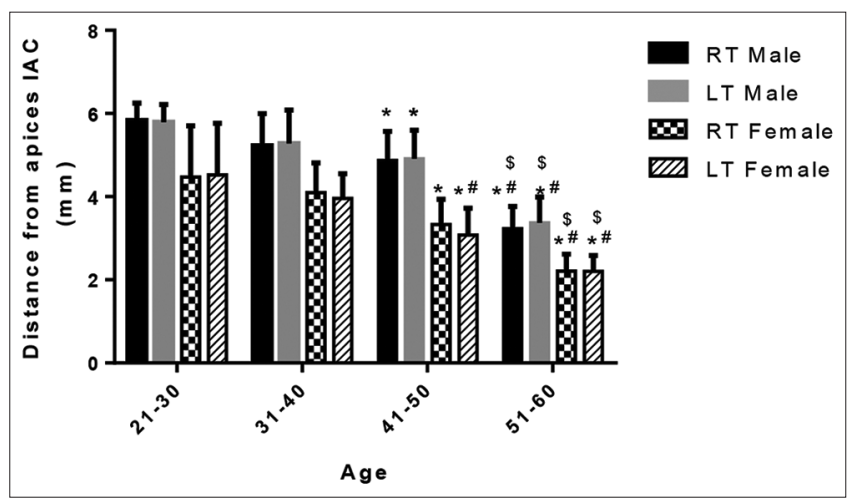

Figure 2: Distance from apices to inferior alveolar canal $(\mathrm{mm})$ in the right and left sides in the different age groups in male and female individuals. ${ }^{*} p<0.05$ versus $21-30$ of the same respective side and same gender, $\# p<0.05$ versus 31-40 group of the same respective side and same gender, and $\$ p<0.05$ versus $41-50$ group of the same respective side and same gender

Statistical difference between right and left sides and between male and females of the same age groups as well as between different age groups of the same sex is illustrated in Figures 2-4 and Tables 1-3.

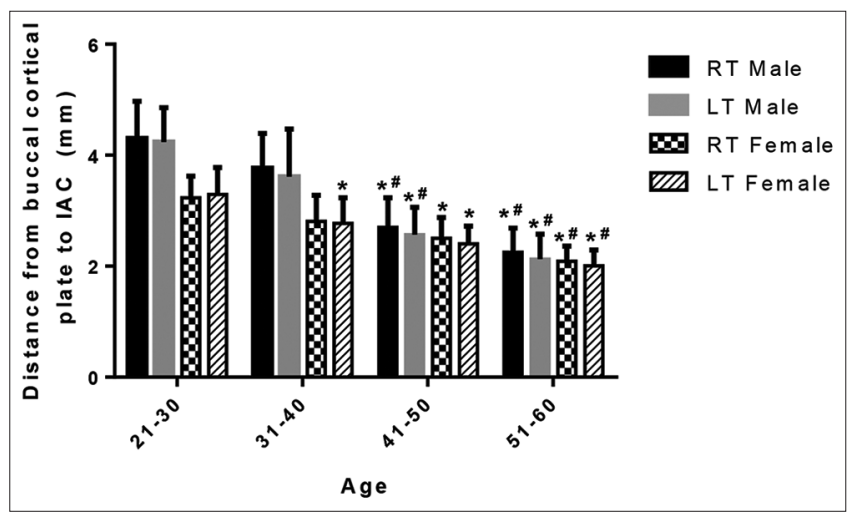

Figure 3: Distance from buccal cortical plate to inferior alveolar canal $(\mathrm{mm})$ in the right and left sides in the different age groups in male and female individuals. ${ }^{*} p<0.05$ versus $21-30$ of the same respective side and gender, $\# p<0.05$ versus 31-40 group of the same respective side and gender

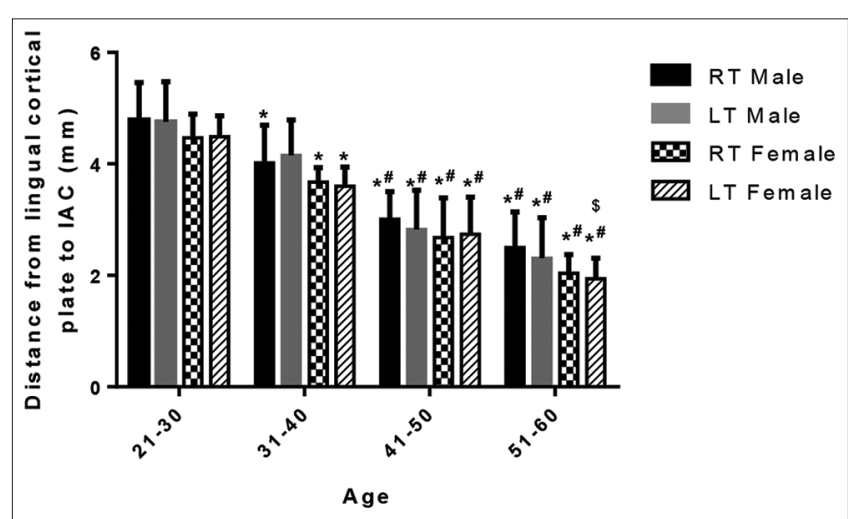

Figure 4: Distance from lingual cortical plate to inferior alveolar canal $(\mathrm{mm})$ in the right and left sides in the different age groups in male and female individuals. ${ }^{*} p<0.05$ versus $21-30$ of the same respective side and gender, $\# p<0.05$ versus $31-40$ group of the same respective side and gender, and $\$ p<0.05$ versus $41-50$ group of the same respective side and gender

\section{Discussion}

In an attempted to minimize complications during several dental processes such as impacted lower last molar extraction, during non-surgical root canal procedures as well as dental implant surgeries, which became the most applied prosthetic solution. Application of accurate pre-surgical planning steps is mandatory. One of these steps is determining the exact anatomical location of IAC particularly in replacing posterior teeth to avoid injury of IAC [12], [13], [14].

Table 1: The mean distances between the roots apices of the mandibular first molars and the MC

\begin{tabular}{lllll}
\hline Age group & M DA RT & M DL LT & F DA RT & F DL LT \\
\hline G1 21-30 years & $5.83( \pm 0.42)$ & $5.79( \pm 0.42)$ & $4.47( \pm 1.2)$ & $4.52( \pm 1.24)$ \\
G2 31-40 years & $5.22( \pm 0.77)$ & $5.27( \pm 0.8)$ & $4.1( \pm 0.7)$ & $3.96( \pm 0.59)$ \\
G3 41-50 years & $4.87( \pm 0.7)$ & $4.91( \pm 0.69)$ & $3.33( \pm 0.6)$ & $3.07( \pm 0.65)$ \\
G4 51-60 years & $3.23( \pm 0.5)$ & $3.36( \pm 0.62)$ & $2.21( \pm 0.41)$ & $2.14( \pm 0.42)$ \\
\hline MC: Mandibular canal. & & & &
\end{tabular}

Damage to IAN is a serious complication that may result in numbness, altered sensation and ache of the lower lip and chin [15]. To avoid damage of the IAN, it is crucial to determine the site and shape of the MC before dental implant surgery. Determination of the site of the $\mathrm{MC}$ is an essential information to clinicians, it can influence the dental implant surgery [16], [17], [18].

Table 2: The mean distances between the MC and the buccal cortical bone of the mandibular first molars

\begin{tabular}{lllll}
\hline Age group & M DA RT & M DL LT & F DA RT & F DL LT \\
\hline G1 21-30 years & $4.3( \pm 0.62)$ & $4.23( \pm 0.62)$ & $3.23( \pm 0.39)$ & $3.29( \pm 0.48)$ \\
G2 31-40 years & $3.77( \pm 0.62)$ & $3.61( \pm 0.86)$ & $2.81( \pm 0.47)$ & $2.77( \pm 0.46)$ \\
G3 41-50 years & $2.7( \pm 0.53)$ & $2.57( \pm 0.49)$ & $2.5( \pm 0.38)$ & $2.4( \pm 0.32)$ \\
G4 51-60 years & $2.25( \pm 0.44)$ & $2.13( \pm 0.45)$ & $2.09( \pm 0.27)$ & $2( \pm 0.29)$ \\
\hline MC: Mandibular canal. & & & &
\end{tabular}

There are several radiographic techniques available to determine the canal position and its relationship to the neighboring structures as digital periapical radiography, panoramic radiography, spiral computed tomography, and CBCT scanning [19]. The 
two-dimensional pictures of periapical radiographs do not reflect the actual anatomical relations between the apices roots and MC. Furthermore, distortion of $2 \mathrm{D}$ panoramic radiograph frequently results in miscalculation of the MC [20], [21].

Table 3: The mean distances between the MC and the lingual cortical bone of the first mandibular molars

\begin{tabular}{lllll}
\hline Age group & M DA RT & M DL LT & F DA RT & F DL LT \\
\hline G1 21-30 years & $4.79( \pm 0.67)$ & $4.75( \pm 1.04)$ & $4.47( \pm 0.42)$ & $4.49( \pm 0.37)$ \\
G2 31-40 years & $4.02( \pm 0.67)$ & $4.15( \pm 0.64)$ & $3.67( \pm 0.26)$ & $3.59( \pm 0.35)$ \\
G3 41-50 years & $3.01( \pm 0) 49$. & $2.82( \pm 0.7)$ & $2.68( \pm 0.7)$ & $2.73( \pm 0.66)$ \\
G4 51-60 years & $2.5( \pm 0.64)$ & $2.3( \pm 0.72)$ & $2.04( \pm 0.33)$ & $1.93( \pm 0.37)$ \\
\hline MC: Mandibular canal. & & &
\end{tabular}

CBCT is reliable, accurate, non-invasive method used to evaluate the proximity of the apices of teeth to the IAC. CBCT has several benefits over other X-ray procedures such as low radiation dose, high resolution, high accuracy, better image quality of teeth and surroundings, fewer artifacts, and low cost compared to computed tomography technique [22].

The findings of our study have revealed that anatomical relationships between mandibular teeth and the $\mathrm{MC}$ are influenced by both age and sex. Distances were decreased in elderly. Also male's values were greater than female values in different age groups.

Our values were difficult to compare with majority of papers, since some authors either grouped all patients of different age groups together and took the mean distances as Hsu et al. [23], while other authors did not divide patient by age decades as we did in our study; Vidya et al. [24] divided patients into three groups, GI from 25 to 30 years, GII 30-35 years, and GIII 32-42 years, no patients older than 42 years were included in the study. Kovisto et al. [25] divided patient into three groups GI $<18 y$, GII from 18 to 48 years and GIII more than 49 years.

Aksoy et al. [26] also divided into three groups GI <21y, Gll from 21 to 40 years and GIII more than 40 years and the oldest patient was 83 years. Although mean distances were difficult to compare, our results showed many agreements with other authors regarding several parameters.

First bilateral comparison between values of right and left sides did not show any statistically significant differences. This is in agreement with many authors [27], [28], [29].

Furthermore, comparing values from male and female in our study showed that DA was high in male than in female of same age group; this is in accordance with numerous studies [25], [26], [29].

Similarly, DB and DC were also higher in males than in females similar to results of several researchers [30], [31]. Furthermore, DA was reduced in elderly, as what was found by many studies [32], [33].

Finally, we would recommend dental practitioners only to measure the distances between teeth apices and MC and the cortical bone thickness only, but also to consider unusual root anatomy as accessory and branching MCs [34].

\section{Conclusion}

Determination of the distance between teeth apices and MC as well as cortical bone thickness, before conducting dental implants and other surgical approach of the lower jaw is critical for ensuring successful surgery and reducing the complications. Our study showed that there was decrease in measurements in older age group in both genders and in female groups more than male groups but with no statistical significant difference. Our data can serve as reference giving a general information about the distance between teeth apices and MC as well as cortical bone thickness for dentists, aiming for determining the optimal implant lengths and location in the mandible.

\section{Ethical Approval}

This study was submitted and approved by the local research committee in the faculty of dentistry, The British University in Egypt.

\section{Authors' Contribution}

Magdy Fouad Youakim: Project development, data analysis. Hisham Moahemd El Shiekh: Data collection, manuscript writing. Sherif Shafik El Bahnasy: Data collection, manuscript writing. Mohamed Shamel: Research submission and publication.

\section{References}

1. Obradović O, Todorovic L, Vitanovic V. Anatomical considerations relevant to implant procedures in the mandible. Bull Group Int Rech Sci Stomatol Odontol. 1995;38(1-2):39-44.

PMid:7881265

2. Davis $\mathrm{H}$. Mobilization of the alveolar nerve to allow placement of osseointegratible fixtures. In: Advanced Osseointegration Surgery: Application in the Maxillofacial Region. Chicago: Quintessence Publishing Co.; 2000. p. 129-41.

3. Promma L, Sakulsak N, Putiwat P, Amarttayakong $P$, lamsaard S, Trakulsuk $\mathrm{H}$, et al. Cortical bone thickness of the mandibular canal and implications for bilateral sagittal split osteotomy: A cadaveric study. Int J Oral Maxillofac Surg. 2017;46:572-7. https://doi.org/10.1016/j.ijom.2016.12.008 PMid:28089388

4. Wadu SG, Penhall B, Townsend GC. Morphological variability of the human inferior alveolar nerve. Clin Anat. 1997;10(2):82-7. https://doi.org/10.1002/ (SICI)1098-2353(1997)10:2<82:AID-CA2>3.0.CO;2-V 


\section{PMid:9058013}

5. Ikeda K, Ho KC, Nowicki BH, Haughton VM. Multiplanar MR and anatomic study of the mandibular canal. AJNR Am J Neuroradiol. 1996;17(3):579-84

PMid:8881258

6. Yu SK, Lee MH, Jeon YH, Chung YY, Kim HJ. Anatomical configuration of the inferior alveolar neurovascular bundle: A histomorphometric analysis. Surg Radiol Anat. 2016;38(2):195201. https://doi.org/10.1007/s00276-015-1540-6 PMid:26272703

7. Serhal $C B$, van Steenberghe $D$, Quirynen $M$, Jacobs $R$. Localisation of the mandibular canal using conventional spiral tomography: A human cadaver study. Clin Oral Implants Res. 2001;12(3):230-6. https://doi. org/10.1034/j.1600-0501.2001.012003230.x

PMid: 11359480

8. Bartling R, Freeman K, Kraut RA. The incidence of altered sensation of the mental nerve after mandibular implant placement. J Oral Maxillofac Surg. 1999;57(12):1408-10. https://doi.org/10.1016/s0278-2391(99)90720-6

PMid: 10596660

9. Hsu JT, Fuh LJ, Tu MG, Li YF, Chen KT, Huang HL. The effects of cortical bone thickness and trabecular bone strength on noninvasive measures of the implant primary stability using synthetic bone models. Clin Implant Dent Relat Res. 2013;15(2):235-61. https://doi. org/10.1111/j.1708-8208.2011.00349.x

\section{PMid:21599830}

10. Hsu JT, Huang HL, Chang $\mathrm{CH}$, Tsai MT, Hung WC, Fuh LJ Relationship of three-dimensional bone-to-implant contact to primary implant stability and peri-implant bone strain in immediate loading: Microcomputed tomographic and in vitro analyses. Int J Oral Maxillofac Implants. 2012;28(2):367-74. https://doi.org/10.11607/jomi.2407

PMid:23527336

11. Hsu JT, Huang HL, Tsai MT, Wu AJ, Tu MG, Fuh LJ. Effects of the $3 \mathrm{D}$ bone-to-implant contact and bone stiffness on the initial stability of a dental implant: Micro-CT and resonance frequency analyses. Int J Oral Maxillofac Surg. 2013;42(2):276-80. https:// doi.org/10.1016/j.ijom.2012.07.002

PMid:22867739

12. Burstein J, Mastin C, Le B. Avoiding injury to the inferior alveolar nerve by routine use of intraoperative radiographs during implant placement. J Oral Implantol. 2008;34(1):34-8. https:// doi.org/10.1563/1548-1336(2008)34[34:AITTIA]2.0.CO;2 PMid:18390241

13. Sarikov R, Juodzbalys G. Inferior alveolar nerve injury after mandibular third molar extraction: A literature review. J Oral Maxillofac Res. 2014;5:e1-5. https://doi.org/10.5037/ jomr.2014.5401

PMid:25635208

14. Rowe $\mathrm{AH}$. Damage to the inferior dental nerve during or following endodontic treatment. Br Dent J. 1983;155(9):306-7. https://doi.org/10.1038/sj.bdj.4805219

PMid:6580031

15. Westermark $A$, Bystedt $H$, von Konow L. Inferior alveolar nerve function after sagittal split osteotomy of the mandible: Correlation with degree of intraoperative nerve encounter and other variables in 496 operations. Br J Oral Maxillofac Surg. 1998;36(6):429-33. https://doi.org/10.1016/s0266-4356(98)90458-2 PMid:9881784

16. Kubilius R, Sabalys G, Juodzbalys G, Gedrimas V. Traumatic damage to the inferior alveolar nerve sustained in course of dental implantation. Possibil Prev Stomatol. 2004;6(4):106-10.

17. Levine $\mathrm{MH}$, Goddard AL, Dodson TB. Inferior alveolar nerve canal position: A clinical and radiographic study. J Oral Maxillofac Surg. 2007;65(3):470-4. https://doi.org/10.1016/j. joms.2006.05.056

PMid:17307595

18. Rueda S, Gil JA, Pichery R, Alcañiz M. Automatic segmentation of jaw tissues in CT using active appearance models and semiautomatic landmarking. Med Image Comput Comput Assist Interv. 2006;9(1):167-74. https://doi.org/10.1007/11866565_21 PMid: 17354887

19. Kim TS, Caruso JM, Christensen H, Torabinejad $M$. A comparison of cone-beam computed tomography and direct measurement in the examination of the mandibular canal and adjacent structures. J Endod. 2010;36(7):1191-4. https://doi. org/10.1016/j.joen.2010.03.028 PMid:20630297

20. Yang J, Cavalcanti MG, Ruprecht A, Vannier MW. 2-D and 3-D reconstructions of spiral computed tomography in localization of the inferior alveolar canal for dental implants. Oral Surg Oral Med Oral Pathol Oral Radiol Endod. 1999;87(3):369-74. https:// doi.org/10.1016/s1079-2104(99)70226-x PMid:10102603

21. Serhal $C B$, Jacobs $R$, Flygare $L$, Quirynen $M$, van Steenberghe D. Perioperative validation of localisation of the mental foramen. Dentomaxillofac Radiol.2002;31(1):39-43. https://doi.org/10.1038/sj/dmfr/4600662 PMid:11803387

22. Huang CY, Liao YF. Anatomical position of the mandibular canal in relation to the buccal cortical bone in Chinese patients with different dentofacial relationships. J Formos Med Assoc. 2016;115:981-90. https://doi.org/10.1016/j.jma.2015.10.004 PMid:26723862

23. Hsu JT, Huang HL, Fuh LJ, Li RW, Wu J, Tsai MT, et al. Location of the mandibular canal and thickness of the occlusal cortical bone at dental implant sites in the lower second premolar and first molar. Comput Mathematical Methods Med 2013;2013:608570. https://doi.org/10.1155/2013/608570

PMid:24302975

24. Vidya KC, Pathi J, Rout S, Sethi A, Sangamesh NC. Inferior alveolar nerve canal position in relation to mandibular molars: A cone-beam computed tomography study. Natl J Maxillofac Surg. 2019;10(2):168-74. https://doi.org/10.4103/njms. NJMS_53_17 PMid:31798251

25. Kovisto T, Ahmad M, Bowles WR. Proximity of the mandibular canal to the tooth apex. J Endod. 2011;37(3):311-5. https://doi. org/10.1016/j.joen.2010.11.030

PMid:21329813

26. Aksoy U, Aksoy S, Orhan K. A cone-beam computed tomography study of the anatomical relationships between mandibular teeth and the mandibular canal, with a review of the current literature. Microsc Res Tech. 2018;81(3):308-14. https://doi.org/10.1002/ jemt.22980 PMid:29285826

27. $\mathrm{Yu} \mathrm{IH}$, Wong YK. Evaluation of mandibular anatomy related to sagittal split ramus osteotomy using 3-dimensional computed tomography scan images. Int J Oral Maxillofac Surg. 2008;37(6):521-8. https://doi.org/10.1016/j.ijom.2008.03.003 PMid: 18450425

28. Bürklein S, Grund C, Schäfer E. Relationship between root apices and the mandibular canal: A cone-beam computed tomographic analysis in a German population. J Endod. 2015;41(10):1696700. https://doi.org/10.1016/j.joen.2015.06.016 PMid:26277053

29. Kawashima Y, Sakai O, Shosho D, Kaneda T, Gohel A. Proximity of the mandibular canal to teeth and cortical bone. J Endod. 
2016;42(2):221-4. https://doi.org/10.1016/j.joen.2015.11.009 PMid:26725176

30. Yoshioka I, Tanaka T, Khanal A, Habu M, Kito S, Kodama M, et al. Relationship between inferior alveolar nerve canal position at mandibular second molar in patients with prognathism and possible occurrence of neurosensory disturbance after sagittal split ramus osteotomy. J Oral Maxillofac Surg. 2010;68(12):30227. https://doi.org/10.1016/j.joms.2009.09.046 PMid:20739116

31. Huang CS, Syu JJ, Ko EW, Chen YR. Quantitative evaluation of cortical bone thickness in mandibular prognathic patients with neurosensory disturbance after bilateral sagittal split osteotomy. J Oral Maxillofac Surg. 2013;71(12):2153.e1-10. https://doi. org/10.1016/j.joms.2013.08.004

PMid:24135253
32. Simonton JD, Azevedo B, Schindler WG, Hargreaves KM. Ageand gender-related differences in the position of the inferior alveolar nerve by using cone beam computed tomography. J Endod. 2009;35(7):944-9. https://doi.org/10.1016/j. joen.2009.04.032

PMid: 19567312

33. Adiguzel $\mathrm{O}$, Yiğit-Ozer $\mathrm{S}$, Kaya $\mathrm{S}$, Akkuş Z. Patient-specific factors in the proximity of the inferior alveolar nerve to the tooth apex. Med Oral Patol Oral Cir Bucal. 2012;17(6):e1103-8. https://doi.org/10.4317/medoral.18190 PMid:22926478

34. Ngeow WC, Chai WL. The clinical anatomy of accessory mandibular canal in dentistry. Clin Anat. 2020;33(8):1214-27. https://doi.org/10.1002/ca.23567

PMid:31943382 